\title{
Okul Öncesi Eğitime Devam Eden Çocukların Trafik Farkındalığının Bazı Değişkenler Açısından İncelenmesi (Şanlıurfa Hilvan Örneği)
}

\section{The Analysis of Traffic Awareness in Pre-School Children in Terms of Certain Variables:The Case of Hilvan/Şanlıurfa}

Yüksek Lisans Öğrencisi, Fatma Tuğçe Çelik, Gazi Üniversitesi, Eğitim Bilimleri Enstitüsü, Okul Öncesi Eğitimi B.D., ftugce.kurt@gmail.com

Doç. Dr., Hatice Bekirr1, Gazi Üniversitesi, Gazi Eğitim Fakültesi, Temel Eğitim Bölümü, Okul Öncesi Eğitimi A.B.D., hsimsekbekir@gmail.com

Prof. Dr., Neriman Aral, Ankara Üniversitesi Sağlık Bilimleri Fakültesi Çocuk Gelişimi Bölümü, aralneriman@gmail.com

Yüksek Lisans Öğrencisi, Remzi Aydın, Gazi Üniversitesi, Eğitim Bilimleri Enstitüsü, Drama ve Eğitim A.B.D., remziaydin@msn.com, remziaydin88@gmail.com

\section{$\ddot{O} z$}

Araştırmada, okul öncesi eğitime devam eden beş yaş çocukların trafik farkındalığını belirlemek, trafik farkındalı̆̆ında cinsiyet, devam edilen kurum türü ve anne baba öğrenim durumunun etkili olup olmadığını incelemek amaçlanmıştır. Tarama modelinde olan bu çalş̧maya Urfa ili Hilvan ilçesinde okul öncesi dönem çocuklarına yönelik olarak gençlik merkezi bünyesinde açlan akıl oyunları-zeka kulübüne ve eğlence merkezine katılan 56'sı anaokuluna, 44'ü ise anasınıfına devam eden beş yaş, çalışmaya gönüllü katılan ve normal gelişim gösteren toplam 100 çocuk dahil edilmiştir. Çalısmada çocuk ve ailesi hakkında bilgi edinebilmek amacıyla Genel Bilgi Formu ile çocukların trafik farkındalıklarını belirlemek amacıyla Aral vd. (2016) tarafindan geliştirilen "Trafik Bilinci Değerlendirme Ölçeği-Çocuk Formu" kullanılmıştır. Verilerin toplanma sürecinde çocuklar ayrı ayrı bir sınıfa alınmış ve veri toplama süresi her çocuk için ortalama 15-20 dakika sürmüştür. Verilerin analizinde \%95 güven düzeyi ile çalışılmış ve verilerin normal dağılım gösterip göstermediği analiz edilmiştir. Analizler sonucunda veriler normal dağılım göstermediği için parametrik olmayan test tekniklerinden Mann Whitney U ve Kruskal Wallis testleri kullanılmışıı Farklılığa yönelik yapılan analizlerde $(k>2)$, anlamlı farklılık bulunan gruplardaki farklılaşmanın nereden kaynaklandığının belirlenmesinde Mann Whitney U testi kullanılmıştır. Araştırma sonucunda çocukların trafik farkındalıklarının orta düzeyde olduğu belirlenmiştir. Trafik Bilinci Değerlendirme Ölçeğinden elde edilen puan ortalamasının baba öğrenim durumuna göre anlamlı düzeyde farklı olduğu $\left(X^{2}=14,042 ; p<0,05\right)$ saptanmıştır. $\mathrm{Bu}$ farklılı̆ın hangi gruplardan kaynaklandığını belirlemek üzere yapılan "Mann Whitney-U”" testi sonucunda üniversite mezunu olan babaların çocuklarının trafik konusundaki farkındalıklarının okuma yazma bilmeyen, ilkokul, ortaokul ve lise mezunu olan babaların çocuklarına göre daha yüksek olduğu görülmüştür. Ayrıca okuma

\footnotetext{
${ }^{1}$ Sorumlu Yazar
} 
yazma bilmeyen babaların çocuklarının trafik konusundaki farkındalıklarının ortaokul ve lise mezunu olan babaların çocuklarına göre daha düşük olduğu görülmüştür. Çocukların cinsiyet, okul öncesi eğitime devam ettikleri kurum türü, anne öğrenim düzeyinin Trafik Bilinci Değerlendirme Ölçeği puan ortalamalarında istatistiksel olarak anlamlı düzeyde bir farklılık oluşturmadığı saptanmıştır.

Anahtar Kelimeler: Trafik farkındalığı, trafik bilinci, okul öncesi eğitim, Şanlıurfa

\begin{abstract}
In this study it is aimed to determine traffic awareness in 5 year old pre-school children and analyze whether gender, type of the institution, and educational status of parents are effective in traffic awareness. In this survey method study, 100 volunteer children who had normal development were included. 56 of them were enrolled in mind games-intelligence club opened for pre-school children in a youth center in Hilvan district of Şanliurfa and 44 of them were 5 year old children enrolled in kindergarten. In order to obtain information on the child and family, general information form was used and Traffic Awareness Assessment Scale - Children's Form developed by Aral et al (2016) was conducted. Data collection was carried out individually in approximately 15-20 minutes for each. In data analysis, reliability was determined as 95\% and the analysis of normal distribution of data was done. As non-normal distribution of data was observed, Mann Whitney U and Kruskal Wallis tests were used. In the analysis regarding difference $(k>2)$, the source of the difference found in groups with significant difference was found out with Mann Whitney U test. Results showed that children had medium level traffic awareness. The average score obtained from Traffic Awareness Assessment Scale indicated that father's education status showed a significant difference $\left(\mathrm{X}^{2}=14,042 ; \mathrm{p}<0,05\right)$. Mann Whitney- $\mathrm{U}$ test conducted to evaluate from which group this difference arose showed that children of university graduate fathers had higher traffic awareness comparing to those of illiterate, primary school, secondary school and high school graduate fathers. Besides, children of illiterate fathers had lower traffic awareness than those of secondary and high school graduate fathers. In the average scores obtained in Traffic Awareness Assessment Scale, no statistically significant difference was observed in terms of gender, type of institution and educational status of mothers.
\end{abstract}

Keywords: Traffic awareness, traffic consciousness, preschool education, Şanlıurfa

\title{
Giriş
}

Çocuğun içinde bulunduğu çevrede sıklıkla tanık olduğu trafikte yaşama hakkını güvence altına almanın en güzel yolu okul öncesi dönemden itibaren trafik bilinci oluşturulması ve trafik eğitiminin verilmesidir(Sarıçiçek ve Bekir, 2018). Okul öncesi dönem geleceğin yetişkinleri ve güvencesi olan çocukların trafik hakkında bilgilendirilmeleri ve bilinçlendirilmeleri açısından en önemli kısmı oluşturmaktadır (Hatipoğlu, Özdemir ve Öztürk, 2012).

Ülkemizde meydana gelen trafik kazalarında ve kazalar sonucu meydana gelen ölüm oranlarında son yıllarda azalmalar olmasına rağmen, gelişmiş ülkelerle karşılaştırıldığında çok da iyimser bir tablo ile karşılaşılmamaktadır (Aral vd., 2016). Dünya Sağlık Örgütünün (2014) verilerine göre Ekonomik İşbirliği ve Kalkınma Örgütü (OECD) ülkeleri arasında Türkiye 0-14 yaş kazalarında ölüm oranı en yüksek ülkedir (gateway.euro.who.int, 2018). Türkiye'de kaza istatistiklerinde (karayolu) yer alan yaş grubuna 
göre trafik kazasında ölen ve yaralanan çocuk sayıları incelendiğinde; 0-9 yaş arasında 339 çocuk hayatını kaybederken 22530 çocuk yaralanmıs, 10-14 yaş arasında 159 çocuk hayatını kaybederken 14320 çocuk yaralanmıştır (Türkiye İstatistik Kurumu, 2016). Meydana gelen trafik kazalarında ölen on beş yaşından küçük çocukların toplam ölümler arasındaki oranı bakımından, Türkiye ön sıralarda yer almaktadır. $\mathrm{Bu}$ durum "tehlike" olarak görülmektedir. Türkiye'de acil kliniklerine başvurunun \% 25’ini çocukların oluşturduğu, çocukların büyük oranda trafik kazalarına maruz kaldığı belirtilmiştir (Polat, Güdücü Tüfekçi, Özyazıcıŏlu ve Yazar, 2005; Gökdağı ve Atalay, 2015). Trafik kazalarını en aza indirmenin yolu şüphesiz ki toplumu trafik farkındalı̆̆ ve bilinci konusunda bilgilendirmektir. Çocukların gelecekte trafikte sürücü, trafiği denetleyen, hatta trafik düzeni hakkında karar veren konumda olacakları düşünüldüğünde çocukların doğru ve kalıcı bir trafik farkındalığına sahip olması trafik sorunlarını başlangiçta çözmesi açısından büyük öneme sahiptir.

Ayrıca trafik farkındalığı ve bilinci oluşmuş olan çocuk, o andan itibaren yetişkinleri trafikteki davranışları açısından doğru bilgilerle uyarabilecek ve yönlendirebilecektir (Gürsoy vd., 2015). Tüm bunlar dikkate alındığında bu çalışmada, okul öncesi eğitime devam eden beş yaş çocukların trafik farkındalı̆̆ını belirlemek, trafik farkındalı̆̆ında cinsiyet, devam edilen kurum türü, anne baba öğrenim durumunun etkili olup olmadığını incelemek amaçlanmıştır. Bu çalışmanın erken yaşlardan itibaren trafik eğitimi verilmesine yönelik çalışmaların ve eğitim programların yaygınlaşmasına da katkı sağlayacağı düşünülmektedir.

\section{Yöntem}

Bu bölümde araştırmanın modeli, çalısma grubu, veri toplama araçları, verilerin toplanması ve verilerin analizine yer verilmiştir.

\section{Araştırmanın Modeli}

Okul öncesi eğitime devam eden beş yaş çocukların trafik farkındalığını belirlemek, trafik farkındalığında cinsiyet, devam edilen kurum türü, anne baba öğrenim durumunun etkili olup olmadığını incelemeyi amaçlayan bu çalısmada tarama modeli kullanılmıştır. Karasar (2017)'a göre tarama modeli, var olan bir durumu olduğu şekliyle betimlemeyi amaçlar.

\section{Çalışma Grubu}

Araştırmanın çalışma grubunu Urfa ili Hilvan ilçesinde okul öncesi dönem çocuklarına yönelik olarak gençlik merkezi bünyesinde açlan akıl oyunlar1-zekâ kulübüne ve eğlence merkezine katılan 56's1 anaokuluna, 44’ü ise anasınıfina devam eden beş yaş, çalışmaya gönüllü katılan ve normal gelişim gösteren toplam 100 çocuk oluşturmaktadır. Araştırmaya katılan çocuk ve ebeveynlerinin tanıtıcı Özelliklerini içeren bilgiler Tablo 1'de yer almaktadır. 
Tablo 1.Çalışmaya katılan çocukların ve ailelerinin sosyo-demografik özelliklerinin dağılımı

\begin{tabular}{llrr}
\hline & & $\mathbf{n}$ & $\mathbf{\%}$ \\
\hline \multirow{2}{*}{ Okul } & Anaokulu & 56 & 56,0 \\
& Anasinifi & 44 & 44,0 \\
\hline \multirow{2}{*}{ Kinsiyet } & Kiz & 51 & 51,0 \\
& Erkek & 49 & 49,0 \\
\hline \multirow{3}{*}{ Anne eğitim durumu Sayısı } & 1 kardeş & 32 & 32,0 \\
& 2 Kardeş & 20 & 20,0 \\
& 3 ve daha fazla & 48 & 48,0 \\
\hline \multirow{3}{*}{ Baba eğitim durumu } & Okur yazma bilmiyor ya da okuryazar & 34 & 34,0 \\
& İlkokul mezunu & 47 & 47,0 \\
& Lise mezunu & 9 & 9,0 \\
& Üniversite mezunu & 10 & 10,0 \\
\hline Toplam & Okuma yazma bilmiyor ya da okuryazar & 8 & 8,0 \\
& İlkokul mezunu & 21 & 21,0 \\
& Ortaokul mezunu & 20 & 20,0 \\
& Lise mezunu & 37 & 37,0 \\
\end{tabular}

Tablo 1'e göre araştırmaya katılan çocuklardan anaokuluna gidenlerin oranı \%56,0; anasınıfına gidenlerin oranı $\% 44,0$; kız olanların oranı \%51,0; erkek olanların oranı \%49,0; 3 ve daha fazla kardeşi olanların oranı \%48,0; bir kardeşi olanların oranı \%32,0; 2 kardeşi olanların oranı \%20,0'dir. Çocuklardan annesinin eğitim durumu okur yazma bilmiyor ya da okuryazar olanların oranı $\% 34,0$; ilkokul mezunu olanların oranı $\% 47,0$; lise mezunu olanların oranı $\% 9,0$; üniversite mezunu olanların oranı $\% 10,0$; babasının eğitim durumu okur yazma bilmiyor ya da okuryazar olanların oranı $\% 8,0$; ilkokul mezunu olanların oranı $\% 21,0$; ortaokul mezunu olanların oranı $\% 20,0$; lise mezunu olanların oranı $\% 37,0$; üniversite mezunu olanların oranı \%14,0'dür.

\section{Veri Toplama Araçları}

Çalışmada çocuk ve ailesi hakkında bilgi edinebilmek amacıyla Genel Bilgi Formu ile çocukların trafik farkındalıklarını belirlemek amacıyla Aral vd. (2016) tarafından geliştirilen Trafik Bilinci Değerlendirme Ölçeği-Çocuk Formu kullanılmıştır.

\section{Genel Bilgi Formu}

Çocuk ve ailesi hakkında bilgi edinebilmek amacıyla araştırmacılar tarafindan oluşturulan Genel Bilgi Formu; 7 kapalı uçlu (çocukların cinsiyet, kardeş sayısı, devam ettikleri okul öncesi eğitim kurum türü, ebeveynlerin eğitim ve meslek durumları) soru içermektedir.

\section{Trafik Bilinci Değerlendirme Ölçeği-Çocuk Formu}

Çocukların trafik farkındalıklarını belirlemek amacıyla Aral vd. (2016) tarafindan geliştirilen "Trafik Bilinci Değerlendirme Ölçeği-Çocuk Formu" geçerlik ve güvenilirlik çalışmasının çalışma grubunu Ankara il merkezinde bulunan ve farklı sosyo-ekonomik çevreye sahip iki ilkokulun anasınıfı ve birinci sınıfina devam eden 217 çocuk oluşturmuştur. Aral vd. (2016) çocukların yaş ve gelişim özellikleri dikkate alınarak yapılan literatür çalısmaları doğrultusunda Trafik Bilinci Değerlendirme Ölçeği-Çocuk Formunun resimli olmasına karar verildiğini belirtmiştir. Çocukların gelişim özelliklerine uygun 30 
soru/problem durumu oluşturulmuştur. Araştırmada geçerlik, güvenirlik çalışmasında KR20 iç tutarlılık katsayıs1 0.72 olduğu ve Trafik Bilinci Değerlendirme Ölçeği Çocuk Formunun yap1 geçerliliğinin sınanması adına yapılan açımlayııı faktör analizi ve doğrulayıcı faktör analizinden elde edilen bulgular formun tek faktörlü 17 maddeden oluştuğu tespit edilmiştir. Trafik Bilinci Değerlendirme Ölçeği-Çocuk Formunda yer alan soru/problem durumlarının bir kısmı çoktan seçmeli, bir kısmı ise doğru yanlış yani iki seçenekli olarak hazırlanmıştır. Değerlendirmede çocuktan hem çoktan seçmeli hem de doğru yanlış soru/problem durumu için yanıt vermesi beklenmektedir. Çocuk doğru yanıt verdiğinde 1 , yanlış yanıt 0 puan olarak değerlendirilmektedir. Ölçekten alınabilecek en yüksek puan 17, en düşük puan ise 0'dır (Aral vd., 2016).

\section{Verilerin Toplanmas1}

Veriler toplanmadan önce merkez yönetimi ve öğretmenlere araştırmanın amacından bahsedilmiştir. Araştırmacılar tarafindan Genel Bilgi Formu okul öncesi öğretmenlerinin yantları doğrultusunda doldurulmuştur. Trafik Bilinci Değerlendirme Ölçeği’nin uygulanmasında çocuklar bireysel olarak bir odaya alınmıştır. Ölçeğin uygulama süresi çocuk için ortalama 15-20 dakika sürmüştür.

\section{Verilerin Analizi}

Verilerin analizi SPSS 21 programı ile yapılmış ve \% 95 güven düzeyi ile çalışılmıştır. Çalışmada uygun test seçimi normallik testi sonucuna göre yapılmıştır. Trafik Bilinci Değerlendirme puanı ortalaması ölçeği için yapılan Kolmogorov-Smirnov normallik testi sonucu söz konusu ölçek puanın normal dağılım göstermediği belirlenmiştir. Bu nedenle Trafik Bilinci Değerlendirme puanı ortalaması ölçeği için yapılmış olan gruplar arası karşılaştırma testlerinde parametrik olmayan test teknikleri kullanılmıştır. Çalışmada Trafik Bilinci Değerlendirme Ölçeği puanının demografik değişkenlere göre farklılık gösterme durumu Mann Whitney ve Kruskal Wallis testleri ile analiz edilmiştir. Mann Whitney bağımsız iki grubun nicel bir değişken açısından karşılaştırılmasında, Kruskal Wallis bağımsız k grubun $(k>2)$ nicel bir değişken açısından karşılaştırılmasında kullanılan test tekniğidir. Farklılığa yönelik yapılan analizlerde $(\mathrm{k}>2)$, anlamlı farklılık bulunan gruplardaki farklılaşmanın nereden kaynaklandığının belirlenmesinde Mann Whitney-U testi kullanılmıştır.

\section{Bulgular ve Tartışma}

Araştırmaya katılan çocukların Trafik Bilinci Değerlendirme Ölçeği’nden aldıkları puanların betimsel istatistikleri Tablo 2'de yer almaktadır.

Tablo 2. Araştırmaya katılan çocukların Trafik Bilinci Değerlendirme Ölçeği’nden aldıkları puanlarin betimsel istatistikleri

\begin{tabular}{cccccc}
\hline & n & Minimum & Maximum & Ortalama & ss \\
\hline Trafik Bilinci Değerlendirme Ölçeği & 100 & 2 & 16 & 11,60 & 2,45 \\
\hline
\end{tabular}


Tablo 2 incelendiğinde araştırmaya katılan çocukların Trafik Bilinci Değerlendirme Ölçeği puanı ortalamas1 $11,60 \pm 2,45^{`}$ tir.

Trafik Bilinci Değerlendirme Ölçeğinden alınabilecek en düşük puanın 0, en yüksek puanın 17 olması nedeniyle (Aral vd., 2016) çocukların trafik farkındalıklarının $(11,60 \pm 2,45)$ orta düzeyde olduğu belirlenmiştir. Bu çalışma bulguları Aral vd. (2015)'nin trafik bilincinin oluşmasında oyun temelli trafik eğitiminin etkisini belirlemek amacı ile yaptıkları çalışmanın deney grubu ön test, kontrol grubu ön-son test puan ortalamaları ile benzerlik göstermektedir. Bu durum okul öncesi eğitim alan çocuklara trafik konusunda bir müdahalede bulunulmadığında trafik bilinç ve farkındalıklarının istenilen düzeylere gelemediği şeklinde açıklanabilir. Nitekim Yelmen (2010), Türkiye'de okul öncesi çocukların trafik bilgi ve alışkanlıklarının belirlenmesi başlıklı çalışmasında okul öncesi eğitim alan çocukların trafik konusunda yeteri kadar eğitim görmedikleri sonucuna ulaşmıştır. Ayrıca Hatipoğlu (2011), okul öncesi dönem çocuklarının trafik bilgi ve algılarını belirlemek amacı ile yaptığı araştırma sonucunda çocukların trafik konusundaki bilgilerinin son derece yetersiz olduğunu belirtmiştir.

Araştırmaya katılan çocukların trafik bilinci değerlendirme ölçeği puanlarının cinsiyet değişkenine göre farklılaşma durumları Tablo 3'de yer almaktadır.

Tablo 3.Araştırmaya katılan çocukların Trafik Bilinci Değerlendirme Ölçeği puanlarının cinsiyete göre farklılaşma durumları

\begin{tabular}{llcccc}
\hline Cinsiyet & & n & S1ra Ort. & U & p \\
\hline Trafik Bilinci & Klz & 51 & 50,82 & \multirow{2}{*}{1233,000} & \multirow{2}{*}{, 908} \\
Değerlendirme Ölçeği & Erkek & 49 & 50,16 & & \\
\hline
\end{tabular}

Tablo 3'e göre araştırmaya katılan çocukların Trafik Bilinci Değerlendirme Ölçeği puanlarında kız ile erkek çocuklar arasında istatistiksel olarak anlamlı farklılık bulunmamaktadır ( $\mathrm{p}>0,05)$. Bu bulguya göre çocukların trafik bilincinde cinsiyet değişkeni dışında diğer değişkenlerin daha etkili olduğu söylenebilir. Araştırmaya katılan çocukların trafik bilinci değerlendirme ölçeği puanlarının devam ettikleri okul öncesi eğitim kurumu türüne göre farklılaşma durumları Tablo 4'de yer almaktadır.

Tablo 4.Araştırmaya katılan çocukların Trafik Bilinci Değerlendirme Ölçeği puanlarının devam ettikleri okul öncesi eğitim kurumu türüne göre farklılaşma durumları

\begin{tabular}{llcccc}
\hline Okul & & n & Sıra Ort. & U & p \\
\hline Trafik Bilinci & Anaokulu & 56 & 56,09 & 919,000 & \multirow{2}{*}{$\mathbf{0 2 8}$} \\
Değerlendirme Ölçeği & Anasınıfi & 44 & 43,39 & \\
\hline
\end{tabular}

Tablo 4'e bakıldığında; anaokulu ile anasınıfina giden çocuklar arasında Trafik Bilinci Değerlendirme Ölçeği açısından istatistiksel olarak anlamlı farklılık bulunduğu görülmektedir $(p<0,05)$. Anaokuluna devam eden çocukların söz konusu ölçek için puan sıra ortalamaları 56,09; anasınıfina devam eden ortalamaları 43,39'dur. Buna göre anaokuluna giden çocukların Trafik Bilinci Düzeyleri daha yüksektir. Bu durum çocukların trafik bilincinin oluşmasında anaokullarının anasınıflarına göre daha fazla uyaran ve uygun ortam içerdiğini akla getirmektedir. Stipek, Feiler, Daniels \& Milburn (1995), anasınıflarına göre daha fazla uyarıcıya ve alana sahip olan bağımsız anaokullarına devam eden çocukların beceri gelişiminde, 
akademik başarılarının yükselmesinde ve ebeveynlerinin onayından daha az bağımlı bir şekilde hareket edebilmelerini olumlu etkilediğini belirtmiştir.

Araştırmaya katılan çocukların trafik bilinci değerlendirme ölçeği puanlarının ebeveynlerin eğitim düzeyine göre farklılaşma durumları Tablo 5’te yer almaktadır.

Tablo 5.Araştırmaya katılan çocukların Trafik Bilinci Değerlendirme Ölçeği puanlarının ebeveynlerin eğitim düzeyine göre farklılaşma durumlanı

\begin{tabular}{|c|c|c|c|c|c|c|}
\hline \multicolumn{2}{|c|}{ Anne eğitim durumu } & \multirow{2}{*}{$\frac{\mathbf{n}}{34}$} & \multirow{2}{*}{$\begin{array}{c}\text { Sira Ort. } \\
45,57\end{array}$} & \multirow{3}{*}{$\begin{array}{c}\mathbf{X}^{2} \\
3,649\end{array}$} & \multirow{3}{*}{$\begin{array}{c}\mathbf{p} \\
, 302\end{array}$} & \multirow[t]{2}{*}{$\begin{array}{l}\text { Anlamli } \\
\text { Farklilik }\end{array}$} \\
\hline \multirow{4}{*}{$\begin{array}{l}\text { Trafik Bilinci } \\
\text { Değerlendirme } \\
\text { Ölçeği }\end{array}$} & $\begin{array}{l}\text { Okur yazma bilmiyor ya da } \\
\text { okuryazar }\end{array}$ & & & & & \\
\hline & İlkokul mezunu & 47 & 50,78 & & & \\
\hline & Lise Mezunu & 9 & 51,33 & & & \\
\hline & Üniversite Mezunu & 10 & 65,20 & & & \\
\hline \multicolumn{7}{|c|}{ Baba eğitim durumu } \\
\hline \multirow{5}{*}{$\begin{array}{l}\text { Trafik Bilinci } \\
\text { Değerlendirme } \\
\text { Ölçeği }\end{array}$} & $\begin{array}{l}\text { Okuma yazma bilmiyor ya da } \\
\text { okuryazar }\end{array}$ & 8 & 24,75 & \multirow{5}{*}{14,042} & \multirow{5}{*}{,007 } & \multirow{5}{*}{$\begin{array}{c}1<3,4 \\
5>1,2,3,4\end{array}$} \\
\hline & İlkokul mezunu & 21 & 47,40 & & & \\
\hline & Ortaokul mezunu & 20 & 49,18 & & & \\
\hline & Lise Mezunu & 37 & 50,72 & & & \\
\hline & Üniversite Mezunu & 14 & 71,18 & & & \\
\hline
\end{tabular}

Tablo 5 incelendiğinde anne eğitim durumu farklı olan çocuk gruplanı arasında Trafik Bilinci

Değerlendirme Ölçeği açısından istatistiksel olarak anlamlı farklılık bulunmamaktadır ( $\mathrm{p}>0,05)$.

Araştırmaya katılan çocukların trafik bilinci değerlendirme ölçeği puanlarının baba eğitim düzeyine göre ise istatiksel olarak anlamlı düzeyde farklılaşmaktadır $(\mathrm{p}<0,05)$. Bu farklıllğın hangi gruplardan kaynaklandığını belirlemek üzere yapılan analiz sonucunda baba eğitim durumu okuma yazma bilmiyor ya da okuryazar olan çocukların trafik bilinci $(24,75)$; baba eğitim durumu ortaokul $(49,18)$ ve lise $(50,72)$ mezunu olan çocuklara göre daha düşüktür. Ayrıca babası üniversite mezunu olan çocukların trafik bilinci $(50,72)$; babası okuma yazma bilmiyor ya da okuryazar $(24,75)$; ilkokul $(47,40)$, ortaokul $(49,18)$ ve lise $(71,18)$ mezunu olanlara göre daha yüksektir. Buna göre baba eğitim düzeyi arttıkça çocukların trafik bilincinin de arttı̆̆1 ancak anne eğitim düzeyinin anlamlı bir etki yaratmadığ söylenebilir. Yelmen (2010), çalışmasında okul öncesi çocukların trafik eğitiminde ebeveyn payının çok büyük olduğu bulgusuna ulaşmıştır. Çocuklar trafikteki doğru ya da yanlış tutum ve davranışları ilk olarak ebeveynlerini rol model alarak öğrenirler. Erken dönemde çocuğa verilen trafik güvenliğine ait temel, hayati bilgilerin hayat boyu kalıc1 olacağı ve zamanla bütün toplumu bilinçlendireceği düşünülmektedir (Hatipoğlu, Özdemir \& Arıkan Öztürk, 2012). Eğitimin kalıcı olması içinde öncelikle çocuğun rol model aldığı ebeveynlerin ve bakım veren kişilerin trafik bilinci ve farkındalığına sahip olması önem taşımaktadır. Özellikle Türk toplumunda kadınlar trafikte daha etkin duruma gelmiş olmalarına rağmen, çalışmanın yapıldığı bölgede dikkate alındığında erkekler trafik konusunda daha baskın olarak kabul görmektedir. Bu durum çalışmada çocukların trafik konusunda annelerinden çok babalarını rol model aldıklarını anne eğitim düzeyinin çocukların trafik bilincinde farklılık yaratmadığını akla gelmektedir. 


\section{Sonuç ve Öneriler}

Araştırma sonucunda Trafik Bilinci Değerlendirme Ölçeği’nden elde edilen puan ortalamasının baba öğrenim durumuna göre anlamlı düzeyde farklı olduğu $(p<0,05)$ saptanmıştır. Üniversite mezunu olan babaların çocuklarının trafik konusundaki farkındalıklarının daha yüksek olduğu görülmüştür. Çocukların cinsiyetinin, yaşının, okul öncesi eğitime devam ettikleri kurum türünün ve anne öğrenim düzeyinin Trafik Bilinci Değerlendirme Ölçeği puan ortalamalarında istatistiksel olarak anlamlı düzeyde bir farklılık oluşturmadığı $(\mathrm{p}>0,05)$ saptanmıştır.

Araştırma sonuçlarına yönelik olarak; çocuklara trafik farkındalığı ve bilinci kazandırmaya yönelik etkinliklerin sadece trafik haftası ile sınırlı kalmaması, eğitim dönemi boyunca uygulanması, verilen trafik eğitiminin bilinç ve farkındalığa dönüşmesi açısından ebeveynlerin olumlu rol-model olmalarına sağlamaya yönelik aile katılım çalışmalarının planlanması, trafik ile ilgili çeşitli materyallerin okul öncesi eğitim kurumların öğrenme ortamlarında bulundurulması, okul öncesi dönem çocuklarına yönelik hazırlanan oyun temelli trafik eğitim programlarının uygulanması, araştırmanın daha büyük örneklem ile karma desende tekrarlanması önerilebilir.

\section{Kaynaklar}

Aral, N., Gürsoy, F., Büyüköztürk, Ş., Yıldız-Bıçakcı, M., Can-Yaşar, M., Fındık-Tanrıbuyurdu, E., Özbal, E. \&Aydın, R.(2016, Mart).Erken çocukluk döneminde trafik bilinci değerlendirme ölçeğ̈nin geliştirilmesi: Cocuk, Ebeveyn ve Öğretmen Formu. Uluslararası Erken Çocukluk Eğitimi bildiriler kitabı içinde (ss. 268-281), İstanbul: İstanbul Büyükşehir Belediyesi.

Aral, N., Gürsoy, F., Büyüköztürk, Ş., Yıldız-Bıçakc1, M., Can-Yaşar, M., Fındık-Tanrıbuyurdu, E., Özbal, E. \& Aydın, R.(2015,Kasım).Trafik bilincinin olusmasinda oyun temelli trafik eğitiminin etkisi.6. Karayolu Trafik Güvenliği Sempozyum ve Sergisi (Uluslararası) Sunulan bildiriler 1 kitabı içinde (ss. 228-241), Ankara: Ankara Emniyet Genel Müdürlüğü.

Gökdağ, M. \& Atalay, A. (2015). Trafik eğitiminin trafik kazaları üzerindeki etkisi. Fen Bilimleri Enstitüsü Dergisi, 8 (2), 272-283.

Gürsoy, F.,Aral, N.,Büyüköztürk, Ş., Yıldız-Bıçakc1, M., Can-Yaşar, M., Fındık-Tanrıbuyurdu, E., Özbal, E. \&Aydın, R.(2015). Trafik bilincinin olusmasinda oyun temelli trafik eğitiminin etkisi. Ankara Üniversitesi Bilimsel Araştırma Projesi (12B3430001), Ankara.

Hatipoğlu, S. (2011). Okul öncesi çağı çocuklarının trafik bilgi ve alg1ları. Pegem Eğgitim ve Öğretim Dergisi, 3 , 23-28. 
Hatipoğlu, S., Özdemir, S. \& Arıkan Öztürk, E. (2012). Türkiye'de ilköğretim okullarında verilen trafik eğitiminin farklı ülkelerde verilen eğitimle karşılaştırılarak incelenmesi ve geliştirilmesi için öneriler. Abant İzzet Baysal Üniversitesi Eğitim Fakültesi Dergisi, 12(2), 9-22.

Karasar, N.(2014). Bilimsel araștrma yöntemi: kavramlar ilkeler teknikler. Ankara: Nobel.

Polat, S.,Güdücü Tüfekci, F., Özyazıcıŏ̆lu, N. \& Yazar, F. (2005). Çocuk Acil Kliniğine Başvuran 0-18 Yaş Grubu Olguların İncelenmesi. Atatürk Üniversitesi Hemșirelik. Yüksekokulu Dergisi, 8(2), 55-62.

Sarıçiçek, T. \& Bekir, H. (2018). 5 yaş çocuk resimlerinde trafike. II. Uluslararası Sınırsız Eğitim ve Araştırma Sempozyumu (USEAS 2018) bildiri özetleri kitabı içinde (ss. 215), Ankara: Sınırsız Eğitim ve Araştırma Derneği.

Stipek, F. D. R., Daniels, D. and Milburn S. (1995). Effects of Different Instructional) Approaches on Young Children's Achievement and Motivation. Child Development, 66(1, Feb): 209-223. EJ 501879 .

Türkiye İstatistik Kurumu (2016). Yillara göre ölü ve yaral sayzlarmm yas gruplarna göre dağgllmm.www.tuik.gov.tr/PreIstatistikTablo.do?istab_id=363 sayfasindan 01.05.2018 tarihinde erişilmiştir.

Yelmen, Y.(2010). Türkiye'de okul öncesi çocuklarn trafik bilgi ve alșkanlkklarmm belirlenmesi. Yüksek Lisans Tezi, Gazi Üniversitesi Fen Bilimleri Enstitüsü, Ankara.

https://gateway.euro.who.int/en/indicators/hfamdb 670-sdr-0-14-motor-vehicle-traffic-accidents-per$\underline{100-000 / 20.04 .2018}$ 